\title{
The impact on human health of car-related air pollution in the UK, 1995-2005
}

\author{
T.W. Smith ${ }^{\text {a }}$, C.J. Axon ${ }^{\text {b }}$, R.C. Darton ${ }^{\mathrm{a}, *}$ \\ ${ }^{a}$ Department of Engineering Science, University of Oxford, Parks Road, Oxford OX1 3PJ, UK \\ ${ }^{\mathrm{b}}$ School of Engineering and Design, Howell Building, Brunel University, Uxbridge, London UB8 3PH, UK. \\ * Corresponding author. Tel +44 1865273188 \\ Email addresses Colin.Axon@brunel.ac.uk, richard.darton@eng.ox.ac.uk
}

\begin{abstract}
We have analysed the impact on human health of emissions produced by the UK car fleet in the years 1995 and 2005. Calculations were based on reported measurements of pollutant concentration, literature values of exposure response coefficients and data for mortality and morbidity. A share was attributed to the car fleet based on emissions data. Although the total distance driven in the UK increased by $16 \%$ over this period to 460 billion $\mathrm{km}$, there was a significant fall in engine emissions as increasingly stringent regulations (EURO standards) were introduced. As a result there was a decrease of some $25 \%$ in the number of deaths attributable to car-related air pollution - down to 5589 in 2005. The estimated number of years of life lost at 65000 (England and Wales) in 2005, was about half that caused by road accidents involving cars in the same year. We report further calculations which show the effect of car-related pollution on hospital admissions. Our method is straightforward, providing acceptable estimates for health impacts on the predominantly urban population of the UK. There remains a need for more work, particularly cohort studies of morbidity, to establish the long-term effects of air pollution.
\end{abstract}

Keywords: Air pollution, Emissions, Health, Motor car, Mortality, Morbidity.

\section{Introduction}

Road transportation has a well-documented impact on public health, due to road traffic accidents and as a consequence of vehicle emissions to the atmosphere (Woodcock et al., 2007). Whilst casualties from road collisions are straightforward to quantify and their impact easily understood, increased mortality and morbidity caused by vehicle emissions are harder to measure. Recent years have seen significant changes in several aspects of car-based transportation in the UK. Increasingly stringent regulation of tail-pipe emissions has been implemented through the EURO standards (EC, 2007), which regulate $\mathrm{CO}, \mathrm{NO}_{\mathrm{x}}$, unburnt hydrocarbons, and particulate matter (PM). EURO 2 came into force in 1996, EURO 3 in 2000 and EURO 4 in 2005. This has coincided with significant growth in the volume of UK car-based transport: from 395.6 billion vehicle-km (vkm) in 1995 to 459.8 billion vkm in 2005. The UK car fleet (defined as vehicles belonging to the private and light goods tax class) increased in size by $28.6 \%$ over the same period to a total of 29.2 million vehicles in 2005. Between 1995 and 2005 the population increased from 58.0 million to 60.2 million. Quantifying how these changes have affected the impact of the car fleet on public health is not only interesting from a policy perspective, but also helps address the wider question of transport sustainability. Therefore we conducted a study of the UK car fleet using a set of indicators of sustainability generated with the Process Analysis Method (Chee Tahir and Darton, 2010), and as part of this wider assessment, we analysed the impact on human health of emissions produced by the UK car fleet in 1995 and 2005. Our objective was to quantify these impacts and show how they have changed over this 10 -year period.

\section{Impact of Air Emissions on Health}

In their review, Ren and Tong (2008) concluded that air pollution causes consistent short-term effects on hospital admissions and deaths, and that there is evidence linking it to long-term effects. Epidemiological studies of the long-term impacts of particulates on human health have been reviewed by Pope (2007), whilst Sahsuvaroglu and Jerrett (2007) have reviewed studies of the short-term effects of most common pollutants. In the UK, the Committee on the Medical Effects of Air Pollution (COMEAP) has published a series of reports assessing the impacts of air pollution more generally (COMEAP 1998, 2010) and has reviewed 
Final version appeared as: TW. Smith, CJ. Axon, \& RC. Darton (2013). The impact on human health of car-related air pollution in the UK, 1995-2005. Atmospheric Environment, 77, pp. 260-266, DOI:10.1016/j.atmosenv.2013.05.016.

current methodolgies (COMEAP 2001, 2009). This work concluded that $\mathrm{PM}_{2.5}$ (particles in the atmosphere with a diameter of less than ten or equal to a nominal $2.5 \mu \mathrm{m}$ ) is the pollutant most strongly associated with increased risks of mortality. Kunzli et al. (2000) considered the impact of traffic-related particulate emissions in France, Switzerland and Austria. They found that twice as many deaths can be attributed to these emissions as are caused by accidents, although it is noted that the impact in terms of years of life lost is nevertheless greater for accidents, a feature that we attempt to quantify in this study.

There has been limited assessment in the literature of the impact that car-related emissions are having on human health (mortality and morbidity). Mortality is measured in terms of deaths brought forward (DBF) and years of life lost (YOLL), and morbidity in terms of hospital admissions. To quantify these impacts, four key pieces of data are required:

- The average population exposure to air pollutants during the study years;

- An estimate of the share of impact attributable to the car fleet;

- Quantification of the relationship between exposure and response in terms of mortality and morbidity;

- Mortality and hospital admissions data for the study years.

We use measurements for ambient pollutant levels across the UK, Exposure-Response Coefficients (ERCs) found in the literature, and official mortality and morbidity statistics to calculate the total impact of air pollution from all sources. A fraction of this impact is then taken, corresponding to the share of pollution attributable to the car fleet. The calculation is detailed in section 2.2. The choice of ERCs and the method of attributing share both significantly affect the final result, but are both subject to significant uncertainties.

2.1 UK Air quality

Measurements of air quality in the UK are routinely collected on a comparable basis (AEA 2010a) from monitoring stations at nine different types of location including urban, suburban, rural, industrial and roadside areas. We focus on urban and suburban areas as these are the most heavily populated and are the most affected by vehicle emissions. To produce overall estimates for the UK, we averaged the annual mean measurements from urban, suburban and roadside sites, using locations common to both years of study.

The data (Table 1) mostly show the expected overall downward trend in ambient levels of (non- $\left.\mathrm{CO}_{2}\right)$ pollutants in the UK. The only increase over the period is in the concentration of ozone, due in part to decreases in $\mathrm{NO}_{\mathrm{x}}$ emissions. At higher $\mathrm{NO}_{\mathrm{x}}$ concentrations, above $100 \mathrm{ppb}, \mathrm{O}_{3}$ becomes scarce as it reacts to oxidise $\mathrm{NO}$ to $\mathrm{NO}_{2}$ (Mattai and Hutchinson, 2008). Measurements of $\mathrm{PM}_{2.5}$ were not available for 1995 and were only available for four sites in 2005 , so we estimated the $\mathrm{PM}_{2.5}$ concentration by applying a single ratio (from DEFRA, 2005) to the measured concentration of $\mathrm{PM}_{10}$. This method of estimating levels of $\mathrm{PM}_{2.5}$ was also used by Beelen et al. (2008a). From this estimate we subtracted the concentration of $\mathrm{PM}_{2.5}\left(1.42 \mu \mathrm{g} \mathrm{m}^{-3}\right)$ attributed to non-anthropogenic sources by COMEAP (2010), which we assumed constant over the study period.

Table 1. Annual means of ambient levels of air pollutants, $\mu \mathrm{g}^{-3}$, calculated with air quality data from AEA (2010a).

\begin{tabular}{llll}
\hline & $\mathbf{1 9 9 5}$ & $\mathbf{2 0 0 5}$ & Change \\
\hline $\mathrm{PM}_{10}$ & 32.71 & 23.38 & $-28.5 \%$ \\
$\mathrm{PM}_{2.5}$ (Based on single ratio adjustment of $\mathrm{PM}_{10}$ ) & 18.55 & 13.26 & $-28.5 \%$ \\
$\mathrm{PM}_{2.5}$ (Anthropogenic fraction) & 17.13 & 11.86 & $-30.8 \%$ \\
$\mathrm{SO}_{2}$ & 25.11 & 4.77 & $-81.0 \%$ \\
$\mathrm{NO}_{2}$ & 50.50 & 37.43 & $-25.9 \%$ \\
$\mathrm{CO}$ & 850 & 370 & $-56.5 \%$ \\
Ozone (Annual mean of Daily Max 8 Hour Mean) & 53.20 & 56.15 & $5.5 \%$ \\
\hline
\end{tabular}

The car fleet is not the only source of ambient air pollution. In the case of particulates, there is a significant contribution from both natural sources and secondary particles (DEFRA, 2005). Secondary 
Final version appeared as: TW. Smith, CJ. Axon, \& RC. Darton (2013). The impact on human health of car-related air pollution in the UK, 1995-2005. Atmospheric Environment, 77, pp. 260-266, DOI:10.1016/j.atmosenv.2013.05.016.

particles result from the emission of precursor pollutants such as $\mathrm{NO}_{\mathrm{x}}$, Non-Methane Volatile Organic Compounds (NMVOCs), $\mathrm{NH}_{3}$ and $\mathrm{SO}_{2}$, and can involve distant emission sources (Mattai and Hutchinson, 2008). Another complicating factor is the re-suspension of road dust, brought about by turbulence in the wake of moving vehicles for example. Actual emission rates depend upon factors such as road surface, vehicle type and the weather. Source apportionment of particulates is therefore uncertain, even if sophisticated models are used. In this study, the share of annual (national) primary emissions was used as a basis for attributing the health impact due to the car fleet. Primary emissions refer to exhaust emissions, particulate emissions from tyre and brake wear and road abrasion, together with NMVOC emissions from gasoline evaporation. Table 2 shows the proportion of national emissions produced by the car fleet based on data from the National Atmospheric Emissions Inventory (Summary Emission Estimate Datasets 2010 AEA, 2010b) ${ }^{1}$. We consider only direct vehicle emissions resulting from vehicle operation which have the clearest impact on ambient air quality in populated areas, and not embodied emissions which are related to manufacturing and disposal.

Table 2. UK car fleet's share of national emissions.

\begin{tabular}{lllll}
\hline & \multirow{2}{*}{$\begin{array}{l}\text { Change in national, } \\
\text { all source emissions, }\end{array}$} & \multicolumn{3}{l}{ Share of national emissions, car fleet } \\
\cline { 4 - 5 } & $\mathbf{1 9 9 5}$ to 2005 & $\mathbf{1 9 9 5}$ & $\mathbf{2 0 0 5}$ & $\begin{array}{l}\text { Percentage } \\
\text { Point Change }\end{array}$ \\
\hline $\mathrm{PM}_{10}$ & $-38.3 \%$ & $12.3 \%$ & $16.2 \%$ & $3.9 \%$ \\
$\mathrm{PM}_{2.5}$ & $-37.8 \%$ & $16.8 \%$ & $20.3 \%$ & $3.5 \%$ \\
$\mathrm{SO}_{2}$ & $-70.0 \%$ & $1.2 \%$ & $0.3 \%$ & $-0.9 \%$ \\
$\mathrm{NO}_{x}$ & $-31.8 \%$ & $32.4 \%$ & $21.6 \%$ & $-10.8 \%$ \\
$\mathrm{NMVOC}$ & $-51.1 \%$ & $33.7 \%$ & $16.5 \%$ & $-17.2 \%$ \\
$\mathrm{NH} 3$ & $-29.0 \%$ & $2.5 \%$ & $2.5 \%$ & $0.0 \%$ \\
$\mathrm{CO}$ & $-53.5 \%$ & $68.9 \%$ & $57.5 \%$ & $-11.4 \%$ \\
\hline
\end{tabular}

It is important to note that ambient levels of air pollution (Table 1) which show what is actually present in the air, are different to emissions (Table 2) which record what is being emitted into the air. It can be seen that for most pollutants the share of pollution caused by the car fleet has been shrinking. Since overall emissions have been decreasing, car fleet emissions have been falling faster than the national average. The one exception is for particulates (both coarse and fine particles) where the car fleet share of national emissions has actually increased, indicating that for particulates the car fleet is lagging behind the national average reduction in emissions. Tyre and brake wear, as well as road abrasion, are a contributing factor. Since these are non-exhaust emissions improvements in engine technology do not affect them, but the increase in vehicle-km does $(+16.2 \%$ between 1995 and 2005). It is also worth noting that the car fleet produces a higher proportion of national, primary $\mathrm{PM}_{2.5}$ than it does of $\mathrm{PM}_{10}$. $\mathrm{PM}_{2.5}$ constitutes $80-90 \%$ of the $\mathrm{PM}_{10}$ emitted by petrol and diesel engines, which is a much higher fraction than for average particulate emissions.

Table 2 reports nitrogen oxide emissions as $\mathrm{NO}_{\mathrm{x}}$, which comprises both $\mathrm{NO}$ and $\mathrm{NO}_{2}$; relative concentrations of $\mathrm{NO}$ and $\mathrm{NO}_{2}$ are difficult to determine as they are influenced by the concentration of ozone. No share is given for ozone as it is not directly emitted, and is dependent on climate as well as the presence of precursor emissions, namely $\mathrm{NO}_{x}, \mathrm{NMVOCs}, \mathrm{CO}$ and methane (AEA 2010b).

\subsection{Impact on Mortality}

Calculating the mortality burden of air pollution for a specific year presents a number of interesting problems, since mortality rates in the year of interest are affected by air pollution in past years as well. The method we use compares two scenarios for the year under scrutiny - a baseline case with the death rates observed, and an alternative case where these death rates are reduced by an amount based on the levels of air

\footnotetext{
${ }^{1}$ Emissions data file available at http://naei.defra.gov.uk/datachunk.php?f_datachunk_id=270
} 
Final version appeared as: TW. Smith, CJ. Axon, \& RC. Darton (2013). The impact on human health of car-related air pollution in the UK, 1995-2005. Atmospheric Environment, 77, pp. 260-266, DOI:10.1016/j.atmosenv.2013.05.016.

pollution in that year and the corresponding Exposure-Response Coefficient ${ }^{2}$ (ERC). The result produced by this calculation represents the effect of air pollution at a population-wide level. COMEAP (2010) suggests it is most appropriate to describe the results as 'an effect on mortality equivalent to ' $X$ ' deaths.'

The calculation for evaluating the impacts of air pollutants (from all sources) was adapted from Sahsuvaroglu and Jerrett (2007), but is effectively that used by COMEAP (2010). If DBF is deaths brought forward, $D_{y}$ is mortality in the year under consideration, $D_{y 0}$ is the notional mortality in the complete absence of pollution and $P C$ is ambient pollutant concentration, we have:

$$
\begin{aligned}
& D B F=D_{y}-D_{y 0} \text { and } D_{y}=D_{y 0}+D_{y 0} . E R C . P C \\
& \text { So } D B F=D_{y}-D_{y} /(1+E R C . P C) .
\end{aligned}
$$

The calculation assumes a linear relationship between pollutant concentrations and health impact. Sahsuvaroglu and Jerrett (2007) introduce a baseline pollutant concentration below which no impact occurs, but this was not done here as there is limited evidence that such a threshold exists. The choice of ERC is critical to the calculated health outcome. ERCs are derived from epidemiological studies, which measure the change in recorded mortality and morbidity due to an increase in a pollutant. There are two types of study: time-series studies for short-term responses (typically a few days), and cohort studies for long-term outcomes of exposure to a higher pollutant concentration.

Sahsuvaroglu and Jerrett (2007) note two points about short-term studies. First, it is unreasonable to assume that short-term responses would be sustained given a permanent change to ambient pollutant concentrations. This is because a short, sudden pollution episode could worsen the state of already frail individuals unaccustomed to higher pollutant concentrations, bringing forward their death or disease by as little as a few days. Thus, in calculating longer-term impacts such as annual mortality attributable to air pollution, the outcome could be inflated. Second, only acute effects are captured, so that the outcome could be severely underestimated through the neglect of chronic impacts. An additional consideration is the type of air quality data used - an annual average is not appropriate for use with ERCs derived from responses to short term changes in air quality. Cohort studies capture the response to both long-term and short-term increases in exposure (COMEAP 2001, 2009). As we aim to assess impacts over a year, cohort studies are most appropriate; Kunzli et al. (2001) recommend the use of cohort studies for the assessment of air pollution related mortality. However, cohort studies are not always available for the outcome and pollutant under scrutiny.

Although there are short-term associations between several pollutants $\left(\mathrm{PM}_{10}, \mathrm{PM}_{2.5}, \mathrm{SO}_{2}, \mathrm{NO}_{2}, \mathrm{CO}\right.$, ozone) and mortality, not all pollutants have been linked to long-term effects. COMEAP (2009) recommends $\mathrm{PM}_{2.5}$ as the quantitative assessment index of all-cause mortality for policy interventions, adding that the evidence relating to common air pollutant gases such as $\mathrm{SO}_{2}, \mathrm{NO}_{2}$ and ozone is less well developed. For ozone, Jerret et al. (2009) detected no increase in all-cause mortality in a cohort study. Beelen et al. (2008a) also failed to find significant associations with $\mathrm{SO}_{2}$, although they did find an association with $\mathrm{NO}_{2}$. Keuken et al. (2012) have suggested that elemental carbon (also known as black carbon) provides a more sensitive measure than PM for the purpose of evaluating the health impact of traffic. However, measurements of elemental carbon were not available for the study years. Therefore, in calculating DBF, we used $\mathrm{PM}_{2.5}$ as the sole marker taking a mean ERC value of a $6 \%$ increase in mortality per $10 \mu \mathrm{g} \mathrm{m}^{-3}$ of $\mathrm{PM}_{2.5}$, with low and high values of $1 \%$ and $12 \%$, respectively, as recommended by COMEAP (2009).

Mortality data are available from the UK Office for National Statistics (ONS, 2005 - Deaths: underlying cause, sex and age-group). The figure taken was for non-traumatic mortality (i.e. annual deaths minus injury and poisoning) in those aged over 30 years in England and Wales. Only those aged over 30 years were considered because the cohort studies on which the ERCs are based applied to that age group. The data were restricted to England and Wales since Scotland and Northern Ireland record their statistics separately, and although the headline figures are available, the age and underlying cause breakdown is not. The total mortality figures used were: 541866 (1995) and 489897 (2005). Urban mortality $\left(\mathrm{D}_{\mathrm{y}}\right.$ in the calculation) was assumed to be $84.9 \%$ of total mortality, equal to the proportion of people living in an urban

\footnotetext{
${ }^{2}$ ERCs are expressed in terms of a percentage increase in an outcome per increment increase in pollutant levels. They are presented with high, low and mean estimates, representing a 95\% confidence interval. In situations when the associations between exposure to a pollutant and a particular event are not clear and comprise more uncertainty, it is possible for ERCs (or at least the low estimate) to be negative.
} 
Final version appeared as: TW. Smith, CJ. Axon, \& RC. Darton (2013). The impact on human health of car-related air pollution in the UK, 1995-2005. Atmospheric Environment, 77, pp. 260-266, DOI:10.1016/j.atmosenv.2013.05.016.

environment (Hutchinson and Pearson, 2004). By bringing together the ERCs, the air quality data, the estimate of the share attributable to the car fleet, and the urban mortality data, estimates can be made of deaths brought forward per million inhabitants due to car emissions (Table 3). There is a wide spread in the estimates of DBF, reflecting uncertainty in the ERC.

Table 3. Deaths brought forward per million inhabitants in England and Wales using long-term cohort studies of $\mathbf{P M}_{2.5}$.

\begin{tabular}{lllll}
\hline & & $\mathbf{1 9 9 5}$ & $\mathbf{2 0 0 5}$ & Change \\
\hline $\begin{array}{l}\text { Total - air pollution } \\
\text { from all sources }\end{array}$ & Low ERC & 133 & 81 & $-39.4 \%$ \\
& Mean ERC & 736 & 457 & $-37.9 \%$ \\
& High ERC & 1347 & 857 & $-36.4 \%$ \\
$\begin{array}{l}\text { Share - attributable } \\
\text { to private and light } \\
\text { goods fleet }\end{array}$ & Low ERC & 22 & & $-26.8 \%$ \\
& Mean ERC & 124 & 16 & $-25.0 \%$ \\
\hline
\end{tabular}

Deaths brought forward does not capture the mortality burden fully unless the age at death is considered also, especially when making comparisons with road casualties. The YOLL per DBF may be fewer than the YOLL due to a fatal car accident. Taking the estimates calculated from the mean ERCs it was possible to assess the total number of YOLL for each year, using the Institute of Occupational Medecine spreadsheets (IOMLIFET - Miller and Hurley, 2006), the same method as COMEAP (2010). The mortality risk at each age was calculated using mortality data disaggregated by age and population. We then calculated the factor, using the ERCs and air quality data, to reduce the mortality risk at each age to what it would be without anthropogenic air pollution. This new mortality risk was then multiplied by the original population data to calculate mortality given no air pollution. The difference at each age in number of deaths between the two cases is then multiplied by the expected remaining life expectancy at each age (again assuming no anthropogenic air pollution) to give total YOLL (Table 4). The YOLL per DBF due to air pollution for the study period are virtually unchanged at approximately 11.7 for 1995 and 11.6 for 2005 .

Table 4. Years of life lost in England and Wales using the mean ERC from long-term cohort studies of PM $\mathbf{P M}_{2.5}$

\begin{tabular}{llll} 
& $\mathbf{1 9 9 5}$ & $\mathbf{2 0 0 5}$ & Change \\
\hline $\begin{array}{l}\text { Total - air pollution from all } \\
\text { sources }\end{array}$ & 500337 & 319072 & $-36.2 \%$ \\
$\begin{array}{l}\text { Share - attributable to the car } \\
\text { fleet }\end{array}$ & 84057 & 64772 & $-22.9 \%$ \\
$\begin{array}{l}\text { YOLL attributable to the car } \\
\text { fleet per million inhabitants }\end{array}$ & 1449 & 1075 & $-25.8 \%$ \\
\hline
\end{tabular}

\subsection{Impact on Morbidity}

Years of life lost does not fully capture the impact on health. Air pollution also increases morbidity which can be calculated in much the same way as the mortality impact, based on numbers of hospital admissions for different primary diagnoses. However, the choice of ERC is complicated since the evidence for effects on morbidity is more fragmented than for mortality. Much is based on time-series studies - only a few cohort studies consider the morbidity impact of chronic exposure.

The literature shows some evidence linking long-term pollution to respiratory problems (Brunekreef, 2007, Götschi et al., 2008, and Schindler et al., 2009). However, none of these studies provided satisfactory ERCs to describe the impact on hospital admissions. Gan et al. (2011) linked long-term exposure to trafficrelated air pollution to an increase in coronary heart disease (CHD) hospitalisation and mortality. An interquartile range elevation $\left(\sim 0.8 \mu \mathrm{g} \mathrm{m}^{-3}\right)$ in black carbon was associated with a $3 \%$ increase in CHD hospitalisation. In England, Forbes et al. (2009) examined the effects of air pollutants on doctor-diagnosed angina, myocardial infarction (stroke), as recorded by the Health Survey for England; data for 1994, 1998 and 2003 showed a weakly positive association between $\mathrm{PM}_{10}$ and cardiovascular (CV) disease. The 
Final version appeared as: TW. Smith, CJ. Axon, \& RC. Darton (2013). The impact on human health of car-related air pollution in the UK, 1995-2005. Atmospheric Environment, 77, pp. 260-266, DOI:10.1016/j.atmosenv.2013.05.016.

magnitude of the effect was large, however: per $10 \mu \mathrm{g} \mathrm{m} \mathrm{m}^{-3}$, a $29 \%$ increase in CV disease for men and a $16 \%$ increase for women.

Beelen et al. (2008a) considered long-term exposure to traffic-related air pollution and the risk of lung cancer, but found only a small effect on non-smokers. Similarly, Gallus et al. (2008) found no clear association between $\mathrm{PM}_{10}$ and lung cancer. However, exhaust from diesel engines has been classified as carcinogenic by the World Health Organisation which found sufficient evidence linking diesel exhaust exposure to increased risk of lung cancer. For example, a cohort mortality study by Attfield et al. (2012) reported such a link, in agreement with many, though not all, previous studies.

A number of time-series morbidity studies were reviewed by Sahsuvaroglu and Jerret (2007), who were able to estimate ERCs for $\mathrm{PM}_{10}, \mathrm{NO}_{2}, \mathrm{SO}_{2}, \mathrm{CO}$ and $\mathrm{O}_{3}$. Dominici et al. (2006), and Bell et al. (2009) performed studies on over nine million Medicare enrolees in the USA, looking at $\mathrm{PM}_{2.5}$ and CO respectively. They found associations between $\mathrm{CO}$ and $\mathrm{CV}$ disease, as well as between $\mathrm{PM}_{2.5}$ and both respiratory and CV diseases. The ERCs produced were lower than those suggested by Sahsuvaroglu and Jerret. However, Dominici et al. (2006) noted that there was considerable heterogeneity in the magnitude of response across the country, depending mainly on the exact composition of the particulate matter. This makes comparisons between different studies difficult. Glorennec and Monroux (2007) conducted a health impact assessment on the effects of $\mathrm{PM}_{10}$ in the city of Caen in France, based on ERCs produced by the European APHEA study (Atkinson et al. 2001). These are closer to those presented by Dominici et al.

Tables 5 and 6 present estimated hospital admissions due to car related air pollution calculated using ERCs from Sahsuvaroglu and Jerret (2007), the APHEA study (Atkinson et al. 2001), and Forbes et al. (2009). Data for hospital admissions were taken from HES (2006). We have omitted the impact from ozone because we are unable to attribute the share, but short-term increases in ozone were also linked to increases in hospital admissions (Sahsuvaroglu and Jerret, 2007). The 'adjusted mean' uses the amended ERC of Sahsuvaroglu and Jerret which allows for a limitation in the statistical analysis software used in many of the time-series studies they reviewed. This adjustment allows for the maximum reported discrepancy of $42 \%$ (Dominici et al., 2002).

Table 5. Estimated 1995 and 2005 respiratory hospital admissions per million inhabitants due to car related air pollution based on ERCs from time series studies (Sahsuvaroglu and Jerret, 2007, ERCs and APHEA ERCs, Atkinson et al., 2001).

\begin{tabular}{llllllllll}
\hline & & \multicolumn{1}{c}{$\mathbf{1 9 9 5}$} & \multicolumn{1}{c}{$\mathbf{2 0 0 5}$} \\
\cline { 3 - 9 } Pollutant & Study & Low & Mean & High & $\begin{array}{l}\text { Adj. } \\
\text { mean }\end{array}$ & Low & Mean & High & $\begin{array}{l}\text { Adj. } \\
\text { mean }\end{array}$ \\
\hline $\mathrm{PM}_{10}$ & S\&J & 26 & 75 & 120 & 45 & 25 & 74 & 120 & 44 \\
$\mathrm{PM}_{10}$ & APHEA & 23 & 34 & 48 & NA & 22 & 33 & 47 & NA \\
$\mathrm{SO}_{2}$ & S\&J & 1 & 4 & 6 & 2 & 0 & 0 & 0 & 0 \\
$\mathrm{NO}_{2}$ & S\&J & 81 & 359 & 601 & 219 & 41 & 187 & 320 & 113 \\
\hline
\end{tabular}

Table 6. Estimated 1995 and 2005 cardiovascular hospital admissions per million inhabitants due to car related air pollution based on ERCs from Sahsuvaroglu and Jerret, (2007), APHEA (Atkinson et al. 2001) and Forbes (2009).

\begin{tabular}{llllllllll}
\hline & & \multicolumn{1}{c}{$\mathbf{1 9 9 5}$} & \multicolumn{7}{c}{$\mathbf{2 0 0 5}$} \\
\cline { 3 - 9 } Pollutant & Study & Low & Mean & High & $\begin{array}{l}\text { Adj. } \\
\text { mean }\end{array}$ & Low & Mean & High & $\begin{array}{l}\text { Adj. } \\
\text { mean }\end{array}$ \\
\hline $\mathrm{PM}_{10}$ & S\&J & 27 & 73 & 116 & 42 & 24 & 65 & 104 & 38 \\
$\mathrm{PM}_{10}$ & APHEA & 11 & 27 & 42 & NA & 10 & 24 & 38 & NA \\
$\mathrm{PM}_{10}$ & Forbes & -773 & 764 & 1119 & NA & -600 & 772 & 1215 & NA \\
$\mathrm{SO}_{2}$ & S\&J & 0 & 2 & 3 & 1 & 0 & 0 & 0 & 0 \\
$\mathrm{NO}_{2}$ & S\&J & 463 & 656 & 830 & 406 & 219 & 314 & 402 & 191 \\
$\mathrm{CO}$ & S\&J & 28 & 133 & 170 & 76 & 9 & 45 & 58 & 26 \\
\hline
\end{tabular}


Final version appeared as: TW. Smith, CJ. Axon, \& RC. Darton (2013). The impact on human health of car-related air pollution in the UK, 1995-2005. Atmospheric Environment, 77, pp. 260-266, DOI:10.1016/j.atmosenv.2013.05.016.

There are uncertainties in estimating the total hospital admissions from the results in Tables 5 and 6. Not only do they not include the contribution from ozone, but it is problematic to assume that the impacts of each pollutant are additive. Although multi-pollutant studies were preferred for deriving the ERCs, it is difficult to isolate the impacts of individual pollutants completely. Brunekreef (2007) noted that the presence of $\mathrm{NO}_{2}$ and particulates was often highly correlated.

The results in Tables 5 and 6 show the effect of the variation encountered between different studies.. The Forbes and APHEA studies examine effects due to $\mathrm{PM}_{10}$ in preference to other gaseous pollutants as $\mathrm{PM}_{10}$ showed the clearest associations with morbidity. Tables 5 and 6 only describe morbidity in terms of hospital admissions. There are other measures of morbidity such as the incidence of bronchitis and asthma in both adults and children (Kunzli et al., 2000), but these are not considered here due to a lack of data.

\section{Discussion}

We discuss two aspects of our work: the methodology used, and the impact of the UK car fleet on health and how this changed between 1995 and 2005.

\subsection{Methodology}

We used four pieces of data in the analysis, three of which introduce uncertainty: the average population exposure to air pollutants during the study years, the estimated share of impact attributable to the car fleet, and the quantification of the relationship between exposure and response in terms of mortality and morbidity.

The population exposure to pollutants was calculated by averaging values measured at appropriate monitoring stations in the UK, a method which does not need detailed geographical modelling. A more accurate method would be to use an air quality model to overlay localised air quality data with census data, and produce a population-weighted average exposure. This was the approach used by COMEAP (2010) to calculate the impact of air pollution in 2008. As a means of estimating the error introduced by our simpler approach, we have made a calculation for the year 2008 and compared this with the COMEAP estimate. Our estimate of mean $\mathrm{PM}_{2.5}$ was $9.76 \mu \mathrm{g} \mathrm{m}^{-3}$, approximately $9 \%$ higher than the COMEAP value of $8.97 \mu \mathrm{g} \mathrm{m}^{-3}$ for population-weighted mean $\mathrm{PM}_{2.5}$ in the UK. This good agreement validates our simpler approach. Since our estimate related to urban and suburban areas, which have higher average concentrations, a slightly higher value was expected, and found.

The attribution of share of impact to the car fleet presents several uncertainties, of which the greatest relates to the treatment of secondary particles. In this paper, the attribution is based only on primary emissions. It is therefore possible that the share attributed to the car fleet is underestimated, although calculation is difficult even when using complex models. In their study of France, Austria and Switzerland (which does consider secondary particles), Kunzli et al. (2000) attribute higher fractions (40-50\%) of ambient air pollution to the car fleet, although other factors could affect this, namely the overall emissions profile of each country. COMEAP (2010) attribute only $6.8 \%$ of anthropogenic $\mathrm{PM}_{2.5}$ in the UK to local traffic, with a higher fraction (13.2\%) for inner London. However, the model used by COMEAP (2010) and described by Stedman et al. (2007) also estimates that approximately $50 \%$ of ambient $\mathrm{PM}_{2.5}$ are secondary particles, suggesting that if the contribution from traffic to secondary particles were considered, the share of ambient $\mathrm{PM}_{2.5}$ attributed to traffic would increase. The model used by the London Atmospheric Emissions Inventory (LAEI - Mattai and Hutchinson, 2008) attributes around 50\% of local pollution to cars, although the model also assumes a high level of background particulates, which they do not attribute to any source. Viana et al. (2008) have reviewed a number of publications dealing with source apportionment of particulate matter between 1987 and 2007. Based on chemical analyses of the particulates, these authors report a range of values for the fraction of $\mathrm{PM}_{2.5}$ and $\mathrm{PM}_{10}$ attributable to all vehicular sources. For the urban background, the $\mathrm{PM}_{2.5}$ fractions varied from about $5 \%$ to $50 \%$ in different European locations, with a mean of approximately $25 \%$. Given that our values in Table 2 refer to passenger and light goods vehicles only, they are in the range expected. Our more straightforward methodology avoids the assumptions implicit in other methods and there are currently insufficient data to justify a different approach.

The choice of ERC has a significant effect on the calculated health outcome. For mortality, there is some consensus on choice of ERC, but the confidence interval is still large, ranging from a low estimate of $1 \%$ per $10 \mu \mathrm{g} \mathrm{m}^{-3}$ increase in $\mathrm{PM}_{2.5}$ to a high estimate of $12 \%$. For morbidity, the uncertainty is greater. The APHEA ERCs are similar to the adjusted mean ERCs of Sahsuvaroglu and Jerret (for $\mathrm{PM}_{10}$ ), probably because both were derived from short-term studies. The Forbes (2009) coefficients, however, suggest a much greater impact of air pollution with a mean increase in morbidity of $26 \%$ per $10 \mu \mathrm{g} \mathrm{m}^{-3} \mathrm{PM}_{10}$. This could be a 
result of the Forbes study capturing chronic effects - when considering mortality, long term studies also captured a much greater impact than short term ones. The impact on mortality, even when using long term studies is a $6 \%$ increase per $10 \mu \mathrm{g} \mathrm{m}^{-3} \mathrm{PM}_{2.5}$, equating to roughly $12 \%$ increase per $10 \mu \mathrm{g} \mathrm{m}^{-3} \mathrm{PM}_{10}$ (COMEAP, 2010); this is still much smaller than the impact on morbidity presented in Forbes (2009). The range of uncertainty in the Forbes (2009) ERCs was also high - the lower bound was actually negative. This is partly caused by 2003 showing a much stronger association than either of the other years, which the authors were not able to explain. It is recommended that future work pay close attention to cohort studies assessing the long-term impact of air pollution on morbidity, with the aim of providing a sounder scientific basis for morbidity ERCs.

Finally we note that although both car-related and total pollution fell over the study period, calculations with the Forbes (2009) ERCs suggest that the impact on morbidity actually increased by $1 \%$. If, as the evidence suggests, morbidity is linked to air pollution, this cannot be possible, and it reveals a limitation in our method. A number of factors are at play, chief of which is the ambient air levels of $\mathrm{PM}_{10}$ reducing by less than $\mathrm{PM}_{10}$ emissions over the period (-28.5\% compared to $\left.-38.3 \%\right)$. This fact, combined with the car fleet's increased share of national emissions and the high value of the Forbes (2009) ERC, leads to the anomalous result in Table 6.

\subsection{Health impacts}

From a mortality perspective, car-related pollution accounted for 5589 DBF in 2005, which is more than twice the total fatalities amongst road users due to collisions involving private and light goods vehicles, which were 2677 that year (DFT, 2006). This suggests that transport policy should pay more attention to the effects of air pollution from the car fleet. The years of life lost must also be considered though. In 2005 YOLL due to fatalities resulting from accidents involving private and light goods vehicles were approximately 113700 , almost twice the estimated impact of car related air pollution of approximately 65 000 YOLL. It is an unfortunate fact that collisions disproportionately involve younger people: the average YOLL for a collision fatality is around 40 years, which is much higher than the YOLL per pollution attributable DBF of about 12 years. Although the impact of car-related air pollution on mortality is important, improving road safety must remain a high priority.

The results for morbidity (tables 5 and 6) suggest that car-related air pollution in 2005 resulted in between 3400 and 46500 hospital admissions. For comparison, in 2005, accidents involving private and light goods vehicles caused 246329 non-fatal casualties, $10 \%$ of which were serious.

The impact on health broadly reduced over the study period. The mean ERC results in Table 3 show that DBF per million inhabitants due to car emissions dropped by 25\% between 1995 and 2005, despite the total distance driven by private and light goods vehicles increasing by $16 \%$ over the period. Years of life lost per million inhabitants reduced by $25.8 \%$. These improvements can be attributed to the significant drop in emissions by the car fleet, a result of increasingly stringent EURO emissions standards (EC, 2007). The EURO 2 standards came into force in 1996, and EURO 3 in 2000. Manufacturers typically make changes to their vehicles ahead of the legislation being enforced and since the fleet is renewed every 14-15 years, by 2005 the majority of the fleet conformed to the 1996 regulations, and approximately $30 \%$ conformed to the 2000 regulations. These regulations are therefore having a measurable positive impact on health. Due to the issues arising from the calculation discussed at the end of Section 3.1, the changes in morbidity are less clear. The Sahsuvaroglu and Jerret (2007) ERCs show a reduction in hospital admissions per million inhabitants of $48.2 \%$, APHEA ERCs (Atkinson et al. 2001) show a reduction of $6.8 \%$ but Forbes (2009) ERCs show an increase of $1 \%$. Nevertheless, it is probable that the reduction in car-related emissions is having a positive effect here too.

\section{Conclusions}

The picture of health impacts resulting from our study of the UK car fleet in 1995 and 2005 is generally positive. Despite a $16 \%$ increase in the number of vehicle-km driven, an absolute reduction in (non- $\left.\mathrm{CO}_{2}\right)$ emissions over this ten-year period has resulted in better ambient air quality, which is calculated to have a beneficial effect on public health. Per million inhabitants, we expect a reduction of about $25 \%$ in the number of deaths brought forward attributable to car-related air pollution. The calculations show that car pollution caused about twice as many deaths as car accidents in 2005, though the years of life lost was about twice as high for deaths in car accidents as for mortality related to car pollution, because a younger age group is 
involved in accidents. Our calculations of morbidity are less conclusive, although it is likely that a similar improvement occurred in hospital admissions. Much of this change can be attributed to increasingly stringent emissions regulations. The introduction of the EURO 4 and 5 standards should continue this trend into the future, as newer vehicles account for an increasing share of the fleet. We note however that though the EURO standards introduce a welcome limitation on engine emissions, health impacts are also caused by pollution from fuel evaporation, brake and tyre wear, and road abrasion.

Our calculations rely on the availability of measurements of air quality in urban areas where most of the population now lives, and on studies of the human health response to the various important pollutants. At present, significant uncertainties in these data, and incomplete coverage, limit the accuracy with which impacts can be estimated. There remains a need for cohort studies to quantify the effects of pollution on morbidity. Such calculations are important in providing the evidential base for regulations and standards. The overall health impact of car-related emissions is significant, and should be more widely recognised as a significant cost of car-based transportation.

\section{References}

AEA, -2010 $<\mathrm{http} / / / \mathrm{www}$.airquality.co.uk/data_and_statistics_home.php> [Accessed June 2010].

AEA, 2010b. National Atmospheric Emissions Inventory. [online] Available at: 〈http://www.naei.org.uk> [Accessed June 2012].

Atkinson, R. W., Anderson, H. R., Sunyer, J., Ayres, J., Baccini, M., Vonk, J. M., Boumghar, A., Forastiere, F., Forsberg, B., Touloumi, G., Schwartz, J., and Katsouyanni, K. 2001. Acute effects of particulate air pollution on respiratory admissions: Results from APHEA 2 project. Air Pollution and Health: A European Approach. American Journal of Respiratory and Critical Care Medicine. 164:1860-1866.

Attfield, M. D., Schleiff, P. L., Lubin, J.H., Blair, A., Stewart, P. A., Vermeulen, R., Coble, J. B. and Silverman, D. T. 2012. The diesel exhaust in miners study: a cohort mortality study with emphasis on lung cancer. Journal of the National Cancer Institute 104(11): 869-883.

Beelen, R., Hoek G, van den Brandt PA, Goldbohm RA, et al., 2008a. Long-Term Effects of Traffic-Related Air Pollution on Mortality in a Dutch Cohort (NLCS-AIR Study), Environmental Health Perspectives, 116 (2), 196-202.

Beelen R, Hoek G, van den Brandt PA, Goldbohm RA, et al., 2008b. Long-term exposure to traffic-related air pollution and lung cancer risk. Epidemiology. 19(5), 702-710.

Bell, M.L., Peng, R.D., Dominici, F., Samet, J.M., 2009. Emergency Hospital Admission for Cardiovascular diseases and Ambient Levels of Carbon Monoxide: Results for 126 United States Urban Counties, 1999-2005. Circulation, 120, 949-955.

Brunekreef B., 2007. Health effects of air pollution observed in cohort studies in Europe. Journal of Exposure Science and Environmental Epidemiology 17 Suppl 2, S61-5.

Chee Tahir A, Darton R.C., 2010. The Process Analysis Method of selecting indicators to quantify the sustainability performance of a business operation. Journal of Cleaner Production 18, 1598-1607

COMEAP, Committee on the Medical Effects of Air Pollutants, 1998. Quantification of the Effects of Air Pollution on Health in the United Kingdom. London, UK: Department of Health.

COMEAP, Committee on the Medical Effects of Air Pollutants, 2001. Statement and Report on Long-Term Effects of Particles on Mortality. London, UK: Department of Health. Available at: <http://www.dh.gov.uk/ab/COMEAP/DH_108596> [Accessed June 2010].

COMEAP, Committee on the Medical Effects of Air Pollutants, 2009. Long-Term Exposure to Air Pollution: Effect on Mortality. London, UK: Department of Health. Available at: <http://www.dh.gov.uk/ab/COMEAP/DH_108151> [Accessed June 2010].

COMEAP, Committee on the Medical Effects of Air Pollutants, 2010. The Mortality Effects of Long-Term Exposure to Particulate Air Pollution in the United Kingdom. London, UK: Department of health. Available at: < http://comeap.org.uk/documents/reports/128-the-mortality-effects-of-long-termexposure-to-particulate-air-pollution-in-the-uk.html> [Accessed March 2011].

DEFRA, 2005. Particulate Matter in the United Kingdom. Air Quality Expert Group, Department for Food and Rural Affairs, London, UK.

DfT, 2006. Road Casualties Great Britain: 2005, Department for Transport, London, UK. 
Final version appeared as: TW. Smith, CJ. Axon, \& RC. Darton (2013). The impact on human health of car-related air pollution in the UK, 1995-2005. Atmospheric Environment, 77, pp. 260-266, DOI:10.1016/j.atmosenv.2013.05.016.

Dominici, F., McDermott, A., Zeger, S.L. and Samet, J.M, 2002. On the Use of Generalized Additive Models in Time-Series Studies of Air Pollution and Health. American Journal of Epidemiology 156(3), 193-203.

Dominici, F., Peng, R.D., Bell, M.L., Pham, L., McDermott, A., Zeger, S.L., Samet, J.M., 2006. Fine Particulate Air Pollution and Hospital Admission for Cardiovascular and Respiratory Diseases. Journal of the American Medical Association 295(10), 1127-1134.

EC, 2007. Regulation (EC) No 715/2007 of the European Parliament and of the Council of 20 June 2007 on type approval of motor vehicles with respect to emissions from light passenger and commercial vehicles (Euro 5 and Euro 6) and on access to vehicle repair and maintenance information, European Commission, Brussels, Belgium. Available at: http://eurlex.europa.eu/LexUriServ/LexUriServ.do?uri=CELEX:32007R0715:EN:NOT

Forbes, L.J.L., Patel, M.D., Rudnicka, A.R., Cook, D.G., Bush, T., Stedman, J.R., Whincup, P.H., Strachan, D.P., Anderson, H.R., 2009. Chronic Exposure to Outdoor Air Pollution and Diagnosed Cardiovascular disease: meta-analysis of three large Cross-Sectional Surveys. Environmental Health.

Gallus S, Negri E, Boffetta P, McLaughlin JK, Bosetti C, La Vecchia C., 2008. European Studies on Longterm Exposure to Ambient Particulate Matter and Lung Cancer. European Journal of Cancer Prevention 17(3), 191-194.

Gan, W. Q., Koehoorn, M., Davies, H.W., Demers, P.A., Tamburic, L., Brauer, M., 2011. Long-Term Exposure to Traffic-Related Air Pollution and the Risk of Coronary Heart Disease Hospitalization and Mortality. Environmental Health Perspectives 119, 501-507.

Glorennec P, Monroux F., 2007. Health impact assessment of PM10 exposure in the city of Caen, France. Journal of Toxicology and Environmental Health Part A. 1:70(3-4), 359-364.

Götschi T, Heinrich J, Sunyer J, Künzli N., 2008. Long-term effects of ambient air pollution on lung function: a review. Epidemiology. 19(5), 690-701.

Hospital Episode Statistics (2006), 'Inpatient Data by Primary Diagnosis: Summary', The NHS Information Centre, available at: http://www.hesonline.nhs.uk [Accessed June 2010].

Hutchinson, E. J. and Pearson, P. J. G., 2004. An evaluation of the environmental and health effects of vehicle exhaust catalysts in the United Kingdom. Environmental Health Perspectives, 112 (2), 132141.

Jerrett, M. et al., 2009. Long-Term Ozone Exposure and Mortality. The New England Journal of Medicine, 360 (11), 1085-1095.

Keuken, M.P., Jonker, S., Zandveld, P., Voogt, M., and Elshout van den, S., 2012. Elemental carbon as an indicator for evaluating the impact of traffic measures on air quality and health. Atmospheric Environment 61, 1-8.

Künzli, N., Kaiser, R., Medina, S., Studnicka, M., Chanel, O., Filliger, P., Herry, M., Horak Jr, F., Puybonnieux-Texier, V., Quénel, P., Schneider, J., Seethaler, R., Vergnaud, J-C. and Sommer, H., 2000. Public-health impact of outdoor and traffic-related air pollution: a European assessment. Lancet 356, 795-801.

Kunzli, N., Medina, S., Kaiser, R., Quenel, P., Horak, F., and Studnicka, M., 2001. Assessment of Deaths Attributable to Air Pollution: Should We use Risk Estimates based on Time series Studies or on Cohort Studies? American Journal of Epidemiology 153 (11), 1050-1055.

Mattai, J. and Hutchinson, D., 2008. London Atmospheric Emissions Inventory 2004 Report. London, U.K: Greater London Authority. Available at: http://www.london.gov.uk/sites/default/files/archives/mayorenvironment-air_quality-docs-laei-2004-full-report-dec08.pdf [Accessed April 2013].

Miller, B.G. and Hurley, J.F., 2006. Comparing Estimated Risks for Air Pollution with Risks for Other Health Effects. Edinburgh, UK: Institute of Occupational Medicine. Available at: <http://www.iomworld.org/research/iomlifet.php > [Accessed January 2011].

ONS, 2005. Mortality statistics - Cause. Review of the Registrar General on deaths by cause, sex and age, in England and Wales, 2005. London, U.K: Office for National Statistics.

Pope, C.A., 2007. Mortality effects of longer term exposures to fine particulate air pollution: Review of recent epidemiological evidence. Inhalation Toxicology, 19 (1), 33-38.

Ren, C. and Tong, S., 2008. Health effects of ambient air pollution - recent research development and contemporary methodological challenges. Environmental Health, 7:56. 
Final version appeared as: TW. Smith, CJ. Axon, \& RC. Darton (2013). The impact on human health of car-related air pollution in the UK, 1995-2005. Atmospheric Environment, 77, pp. 260-266, DOI:10.1016/j.atmosenv.2013.05.016.

Sahsuvaroglu, T. and Jerrett, M., 2007. Sources of Uncertainty in Calculating Mortality and Morbidity Attributable to Air Pollution. Journal of Toxicology and Environmental Health - Part A - Current Issues, 70 (3-4), 243-260.

Schindler, C., Keidel, D., Gerbase, M.W., Zemp, E., Bettschart, R., Brandli, O., Brutsche, M.H., Burdet, L., Karrer, W., Knopfli, B., Pons, M., Rapp, R., Bayer-Oglesby, L., Kunzli, N., Schwartz, J., Liu, L-J. S., Ackermann-Liebrisch, U., Rochat, T., SAPALDIA team, 2009. Improvements in PM $_{10}$ Exposure and Reduced Rates of Respiratory Symptoms in a Cohort of Swiss Adults (SAPALDIA). American Journal of Respiratory and Critical Care Medicine 179, 579-587.

Stedman, J.R. Kent, A.J. Grice, S. Bush, T. J. Derwent, R.G., 2007. A Consistent Method for Modelling PM10 and PM2.5 Concentrations across the UK in 2004 for Air Quality Assessment. Atmospheric Environment 41, 161-172.

Viana, M., Kuhlbusch, T.A.J., Querol, X., Alastuey, A., Harrison, R.M., Hopke, P.K., et al., 2008. Source Apportionment of particulate matter in Europe: A review of methods and results. Journal of Aerosol Science 39, 827-849.

Woodcock, J., Banister, D., Edwards, P., Prentice, A. M. and Roberts, I., 2007. Energy and Health 3 Energy and Transport. Lancet 370, 1078-1088. 